\title{
Noninvasive method to estimate anaerobic threshold in individuals with type 2 diabetes
}

\author{
Marcelo M Sales ${ }^{1}$, Carmen Sílvia G Campbell ${ }^{1}$, Pâmella K Morais ${ }^{1}$, Carlos Ernesto ${ }^{1}$, Lúcio F Soares-Caldeira ${ }^{2}$ \\ Paulo Russo ${ }^{3}$, Daisy F Motta ${ }^{4}$, Sérgio R Moreira ${ }^{5}$, Fábio Y Nakamura ${ }^{6}$, Herbert G Simões ${ }^{1 *}$
}

\begin{abstract}
Background: While several studies have identified the anaerobic threshold (AT) through the responses of blood lactate, ventilation and blood glucose others have suggested the response of the heart rate variability (HRV) as a method to identify the AT in young healthy individuals. However, the validity of HRV in estimating the lactate threshold (LT) and ventilatory threshold (VT) for individuals with type 2 diabetes (T2D) has not been investigated yet.
\end{abstract}

Aim: To analyze the possibility of identifying the heart rate variability threshold (HRVT) by considering the responses of parasympathetic indicators during incremental exercise test in type 2 diabetics subjects (T2D) and non diabetics individuals (ND).

Methods: Nine T2D $\left(55.6 \pm 5.7\right.$ years, $\left.83.4 \pm 26.6 \mathrm{~kg}, 30.9 \pm 5.2 \mathrm{~kg} \cdot \mathrm{m}^{2(-1)}\right)$ and ten ND $(50.8 \pm 5.1$ years, $76.2 \pm 14.3$ $\mathrm{kg}, 26.5 \pm 3.8 \mathrm{~kg} \cdot \mathrm{m}^{2(-1)}$ ) underwent to an incremental exercise test (IT) on a cycle ergometer. Heart rate (HR), rate of perceived exertion (RPE), blood lactate and expired gas concentrations were measured at the end of each stage. HRVT was identified through the responses of root mean square successive difference between adjacent R-R intervals (RMSSD) and standard deviation of instantaneous beat-to-beat R-R interval variability (SD1) by considering the last $60 \mathrm{~s}$ of each incremental stage, and were known as HRVT by RMSSD and SD1 (HRVT-RMSSD and HRVTSD1), respectively.

Results: No differences were observed within groups for the exercise intensities corresponding to LT, VT, HRVTRMSSD and HHVT-SD1. Furthermore, a strong relationship were verified among the studied parameters both for T2D ( $r=0.68$ to 0.87$)$ and ND ( $r=0.91$ to 0.98$)$ and the Bland \& Altman technique confirmed the agreement among them.

Conclusion: The HRVT identification by the proposed autonomic indicators (SD1 and RMSSD) were demonstrated to be valid to estimate the LT and VT for both T2D and ND.

\section{Introduction}

The maximal oxygen consumption $\left(\mathrm{VO}_{2 \max }\right)$ and anaerobic threshold (AT) are parameters that have been widely considered as hallmarks of aerobic fitness both for athletes [1], physically active individuals [2] and, in a minor scale, for special populations such as individuals with type 2 diabetes (T2D) [3,4].

Regular exercise provides many physiologic benefits, reduces risk of disease outcomes, and triggers important

\footnotetext{
* Correspondence: hgsimoes@gmail.com

${ }^{1}$ Graduate program in Physical Education of the Catholic University of

Brasilia, Águas Claras, Taguatinga-DF, 72022-900, Brazil

Full list of author information is available at the end of the article
}

psychological gains in healthy and pathological conditions. Moreover, few studies have evaluated the effect of different exercise intensities on T2D [5]. The AT can be used in this specific evaluation and has been considered a gold standard parameter for exercise prescription including cardiovascular risks groups $[3,6]$.

While several studies have identified the AT through the responses of blood lactate $[2,7,8]$ ventilation [9] and blood glucose [7] others have suggested the response of the heart rate variability (HRV) as a method to identify the AT in young healthy individuals [10]. The HRV is a non-invasive measure of the oscillation between consecutive cardiac cycles (as measured between each $R-R$

\section{() Biomed Central}

(c) 2011 Sales et al; licensee BioMed Central Ltd. This is an Open Access article distributed under the terms of the Creative Commons Attribution License (http://creativecommons.org/licenses/by/2.0), which permits unrestricted use, distribution, and reproduction in any medium, provided the original work is properly cited. 
complex). This technique has been used for the noninvasive evaluation of the sympathetic (SNS) and parasympathetic nervous system (PNS) activity both during resting and low intensity exercise [11].

During low to moderate exercise intensity the heart rate (HR) increase is mainly controlled by the PNS withdrawal [12]. On the other hand, at higher intensities (e.g. above AT), there is a reduction in the parasympathetic modulation concomitant to an increase in sympathetic activity $[13,14]$ and thus a decrease in HRV is observed [15]. Such transition between the increase in the SNS activity and the vagal tone withdrawal occurs close to $60 \% \mathrm{VO}_{2 \max }$, being close to the intensity at which the lactate (LT) and ventilatory (VT) thresholds have been observed for healthy young individuals $[10,15]$. However, the validity of the HRV in estimating the LT and VT for individuals who may have autonomic dysfunction associated with T2D [16-18] has not been previously examined.

The HRV as a measure to estimate the AT is noninvasive and inexpensive, providing information regarding the autonomic regulation during exercise. In spite of presenting a higher sympathetic activity during resting and light exercise $[19,20]$ the HRV responses of T2D is thought to be sensitive to predict the LT and VT noninvasively by considering the intensity at which the vagal withdrawal occurs. However, the validity of HRV in estimating the LT and VT for individuals with T2D has not been investigated yet.

Thus, the purposes of present study were 1) to analyze the possibility of identifying the heart rate variability threshold (HRVT) by considering the responses of parasympathetic indicators during incremental exercise test, and 2) to compare and verify the relationships between the HRVT with the VT and LT for individuals with (TD2) and without type-2 diabetes (ND).

\section{Methods}

\section{Participants}

After approval of the local Ethics Committee for Human Research and obtaining written informed consent of the volunteers, 9 T2D individuals, being 4 male and 5 female $\left(55.6 \pm 5.7\right.$ years, $\left.83.4 \pm 23.6 \mathrm{~kg}, 30.9 \pm 5.2 \mathrm{~kg} \cdot \mathrm{m}^{2(-1)}\right)$ and $10 \mathrm{ND}$, being 8 male and 2 female $(50.8 \pm 5.1$ years, 76.2 $\pm 14.3 \mathrm{~kg}, 26.5 \pm 3.8 \mathrm{~kg} \cdot \mathrm{m}^{2(-1)}$ ) participated in this study. Diabetes diagnostic confirmation was conducted through previous medical screening and laboratory measurements such as blood glucose and estimates of glycated hemoglobin $\left(\mathrm{HbA}_{1 \mathrm{c}}\right)$ [21]. The individuals with T2D were on medical and nutritional treatment, using oral hypoglycemiants (Sulfonylureas, Metformin, Metformin+Glibenclamide, Glimepiride, Pioglitazone Chloridrate) and/or controlled food intake. Exclusion criteria for participation in this study included previous diagnosis of peripheral and autonomic neuropathy, retinopathy, as well as diabetic foot ulcerations and orthopedic complications, the use of insulin, and/or use of medicines that would directly affect the HR, or even any other problem that would impair the participants' ability to complete all the study procedures. The general characteristics of the volunteers are presented in table 1 .

\section{General procedures}

All experimental sessions were carried out in the Laboratory of Physical Evaluation and Training (LAFIT) of the Catholic University of Brasília, during the morning period, $2 \mathrm{~h}$ after volunteers had ingested a standardized breakfast consisting of $315.9 \mathrm{kcal}$ as follows: $53 \mathrm{~g}(67.1 \%$ - $212 \mathrm{kcal})$ of carbohydrate; $4.6 \mathrm{~g}(5.8 \%$ - $18.3 \mathrm{kcal})$ of protein and $9.5 \mathrm{~g}(27.1 \%-85.6 \mathrm{kcal})$ of fat, which was considered a moderate glycemic index meal $(\mathrm{GI}=73.9)$. The participants were submitted to a physician evaluation, including resting electrocardiogram (ECG) (ELITE, Micromed $^{\circledR}$ ) and blood pressure (BP) measurements (BP 3AC1-1 Microlife Co.), besides anthropometric measurements and incremental exercise test. During the incremental exercise test, measurements of HR, BP, rate of perceived exertion (RPE), as well as ventilatory and blood lactate variables were continuously monitored.

\section{Incremental exercise test and measurements}

The incremental test (IT) was performed on an electromagnetic cycle ergometer (Lode Excalibur Sport - Netherlands) with 15 watts of initial workload and 15 watts increments at each 3-min stage until volitional exhaustion, maintaining 60 revolutions per minute. The cardiologist of the laboratory monitored the ECG of the

Table 1 Characteristics of the type 2 diabetics individuals (T2D) $(n=9)$ and non diabetics individuals (ND) $(n=10)$

\begin{tabular}{|c|c|c|}
\hline & T2D & ND \\
\hline Age (years) & $55.6 \pm 5.7$ & $50.8 \pm 5.1$ \\
\hline Weight (kg) & $83.4 \pm 23.6$ & $76.2 \pm 14.3$ \\
\hline Height $(\mathrm{cm})$ & $163.1 \pm 10.6$ & $169.0 \pm 9.2$ \\
\hline BMI $\left(k g \cdot m^{2(-1)}\right)$ & $30.9 \pm 5.2$ & $26.5 \pm 3.8$ \\
\hline Time of disease (years) & $6.0 \pm 2.3$ & - \\
\hline Fasting blood glucose $\left(\mathrm{mg} \cdot \mathrm{dL}^{-1}\right)$ & $138.6 \pm 34.2^{*}$ & $91.1 \pm 5.5$ \\
\hline $\mathrm{HbA}_{1 \mathrm{c}}(\%)$ & $6.8 \pm 1.3^{*}$ & $5.2 \pm 0,4$ \\
\hline $\mathrm{VO}_{2 \text { peak }}\left(\mathrm{mL} \cdot \mathrm{kg}^{-1} \cdot \mathrm{min}^{-1}\right)$ & $20.6 \pm 4.3^{*}$ & $29.4 \pm 6.8$ \\
\hline RMSSD $_{\text {rest }}(\mathrm{ms})$ & $21.2 \pm 3.5$ & $26.3 \pm 5.1$ \\
\hline $\mathrm{SD} 1_{\text {rest }}(\mathrm{ms})$ & $15.3 \pm 2.5$ & $20.9 \pm 4.6$ \\
\hline
\end{tabular}

Data expressed as mean ( \pm standard deviation) and standard error of mean for heart rate variability variables (RMSSD and SD1).

$\mathrm{BMI}=$ body mass index; $\mathrm{VO}_{2 \text { peak }}=$ peak oxygen uptake; $\mathrm{HbA}_{1 \mathrm{c}}=$ glycated hemoglobin estimated as suggested Rohlfing et al. [21]; $\mathrm{RMSSD}_{\text {rest }}=$ square root of the mean squared successive differences between adjacent R-R intervals in rest; $S D 1_{\text {rest }}=$ standard deviation of variability instantaneous beatto-beat in rest. ${ }^{*} p<0.05$ in relationship to ND group. 
volunteers throughout the test in order to identify any possible abnormality during exercise.

During the pre-exercise resting, as well as during the last $20 \mathrm{~s}$ of each incremental stage, a $25 \mu \mathrm{L}$ sample of capillarized blood was collected from the ear lobe trough heparinized and calibrated glass capillaries, being deposited in microtubes (Eppendorf) containing $50 \mu \mathrm{L}$ of sodium fluoride $(\mathrm{NaF}) 1 \%$ for latter analyses of the [Lac] through an electroenzimatic method (Yellow Springs 2.700 STAT, OH, USA).

Expired gases were also measured during the IT through a gas analyzer (Metalyzer 3B, Cortex Biophysik, Germany) that was previously calibrated with a 3-L syringe (flow calibration) and a standard mixed gas containing $4.9 \% \mathrm{CO}_{2}$ and $17 \% \mathrm{O}_{2}$ (gas calibration). The values of ventilation $(\mathrm{VE})$, oxygen uptake $\left(\mathrm{VO}_{2}\right)$ and carbon dioxide production $\left(\mathrm{VCO}_{2}\right)$ were recorded during the last $20 \mathrm{~s}$ of each 3-min stage.

During the entire IT, the R-R intervals were recorded (Polar ${ }^{\circledR}$ S810i, Polar Electo Oy, Kempele, Finland) [22] and filtered in the Polar Precision Performance (v. 4.0) software.

\section{Lactate threshold (LT) determination}

The blood lactate kinetics during the IT stages identified the LT, being considered an exercise intensity above which an over proportional increase in blood lactate was observed in relation to increasing workload [1].

\section{Ventilatory threshold (VT) and $\mathrm{VO}_{2 \text { peak }}$ determination}

Expired gases were collected breath by breath and the data from the last 20 seconds. The VT was determined through the analyses of the ventilatory equivalents of $\mathrm{O}_{2}$
$\left(\mathrm{VE} / \mathrm{VO}_{2}\right)$ and $\mathrm{CO}_{2}\left(\mathrm{VE} / \mathrm{VCO}_{2}\right)$, being considered the intensity corresponding to the moment that $\mathrm{VE} /$ $\mathrm{VO}_{2}$ presented an over proportional increase in relation to $\mathrm{VE} / \mathrm{VCO}_{2}$ [23]. $\mathrm{VO}_{2 \text { peak }}$ was considered as the highest oxygen consumption attained at the exhaustion moment [24].

\section{Heart rate variability threshold determination (HRVT)}

Initially, the $\mathrm{R}-\mathrm{R}$ intervals were analyzed by the time domain through the square root of the mean squared successive differences between adjacent R-R intervals (RMSSD). Also, heart rate variability (HRV) was analyzed through the Poincaré plotting technique, from which the instantaneous variability of beat to beat data was derived by means of SD1, according to procedures previously described $[15,25]$

The RMSSD and SD1 corresponded to the R-R interval measures of the last $60 \mathrm{~s}$ of each 3-min stage during the IT. All analyses were run through the HRV Analysis v1.1 software (Biosignal Laboratory, University of Kuopio, Finland).

For the determination of the HRVT, a stabilization point lower than 3 milliseconds (ms) was adopted for of the vagal activity indices (SD1 and RMSSD) plotted against the absolute workload (Figure 1) $[11,25,26]$

\section{Data Analysis}

The data are presented as means $( \pm \mathrm{SD})$. In order to compare the characteristics of the groups, the Student- $t$ test for independent samples was applied. After assessing normality of data through the test of Skewnees and Kurotsis, comparisons between and within groups were done by using an ANOVA for repeated measures, with
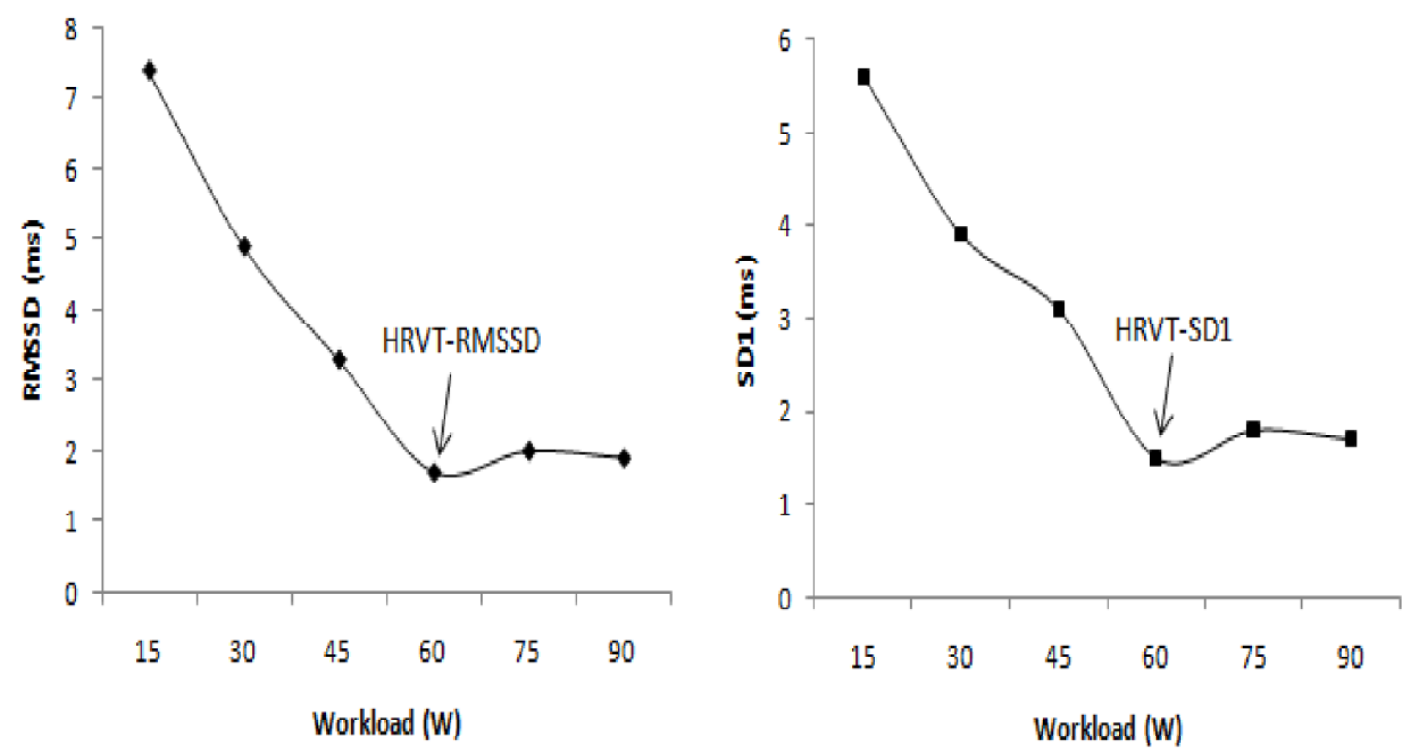

Figure 1 Determination of the heart rate variability threshold (HRVT-RMSSD and HRVT-SD1), for type 2 diabetes mellitus individuals. 
Tukey test as post hoc. The Pearson's product moment correlation was used to verify the relationships among the studied methods to determine AT and the Bland \& Altman technique was applied to verify the agreement among different methods [11,27]. In addition, we also applied the kappa index between the methods of identifying the anaerobic threshold. The significance level adopted was $P<0.05$ (Statistica ${ }^{\circledR}$ version 5.0).

\section{Results}

The results presented in table 2 show no significant differences among the workloads (W) corresponding to AT identified by different methods both groups. For both groups the HR, [Lac], $\mathrm{VO}_{2}$ and RPE corresponding to the AT identified by different techniques did not differ from each other (Table 2). Further, for the T2D group significant correlations $(\mathrm{p}<0.01)$ between LT and peak power $\left(\mathrm{W}_{\text {peak }}\right)(\mathrm{r}=0.89)$, VT and $\mathrm{W}_{\text {peak }}(\mathrm{r}=0.75)$, HRVT-RMSSD and $W_{\text {peak }}(r=0.80)$ and between HRVT-SD1 and $W_{\text {peak }}(r=0.80)$ were observed. High correlations $(\mathrm{p}<0.001)$ were also found in the ND group for the LT and $\mathrm{W}_{\text {peak }}(\mathrm{r}=0.95)$, VT and $\mathrm{W}_{\text {peak }}(\mathrm{r}$ $=0.92)$ and HRVT-RMSSD and $\mathrm{W}_{\text {peak }}(\mathrm{r}=0.89)$ and between HRVT-SD1 $(r=0.90)$. The relationship among exercise intensities (W) corresponding to the studied thresholds are presented in table 3 for both groups.

The Bland and Altman plots showed good agreement for the $\mathrm{VO}_{2}$ corresponding to LT, VT, HRVT-RMSSD and HRVT-SD1 based on the low bias and relatively narrow limits of agreement [Bias $( \pm 95 \%$ of confidence interval)] presented in both groups (T2D and ND) (Table 4 and Figure 2). In addition, the Kappa index also evidenced a good to excellent agreement among studied parameters for both T2D ( $\mathrm{K}=0.66$ to $\mathrm{K}=0.92)$ and $\mathrm{ND}(\mathrm{K}=0.62$ to $\mathrm{K}=0.92)$.

\section{Discussion}

The ability of the HRV responses in estimating LT and VT was investigated in individuals with T2D and ND. The findings confirmed our hypothesis that AT could be identified in T2D through the parasympathetic markers of the HRV responses similarly to ND, being not different and highly correlated to the LT and VT for both groups (Tables 2 and 3, Figure 2). The HRV prediction of AT through autonomic variables such as RMSSD and SD1 has been studied in different populations $[10,15,28,29]$. However, this is the first study in which the AT was identified through HRV responses in $\mathrm{T} 2 \mathrm{D}$, in spite of the fact that this disease is associated with autonomic dysfunction [30,31].

The technique of HRV, as used in the present study, considered a progressive reduction of RMSSD and SD1 to intervals lower than $3 \mathrm{~ms}$ as markers of AT intensity as proposed by others [10,26]. Lima and Kiss [26] found a high relationship between workloads (Watts) corresponding to HRVT and LT for healthy subjects ( $\mathrm{r}=$ 0.76). In this study, even higher correlations were observed between LT and RMSSD threshold ( $\mathrm{r}=0.85$ and $\mathrm{r}=0.94)$ and between LT and SD1 threshold $(\mathrm{r}=$ 0.87 and $r=0.96$ ) for T2D and ND groups, respectively.

The main findings of present study evidenced the HRV as an effective parameter for exercise evaluation in individuals with T2D, due to its noninvasive characteristic as well as because it evaluates variables associated with autonomic function. According to Yeckel et al. [30] the autonomic dysfunction usually precedes the occurrence of T2D. In addition, an elevated sympathetic activity is associated to a higher risk for cardiovascular events such as infarction and stroke [32,33]. The HRVT seems to identify an exercise intensity that represents the transition from a lower to a higher sympathetic

Table 2 Mean ( \pm SD) of workload, blood lactate, heart rate and the rate of perceived exertion corresponding to the lactate (LT), ventilatory (VT) and heart rate variability thresholds (HRVT-RMSSD and HRVT-SD1)

\begin{tabular}{|c|c|c|c|c|c|c|}
\hline & Parameter & Worload (W) & $\mathrm{VO}_{2}\left(\mathrm{~mL} \cdot \mathrm{kg}^{-1} \mathrm{~min}^{-1}\right)$ & [LAC] $\left(\mathrm{mmol} . \mathrm{L}^{-1}\right)$ & HR (bpm) & RPE (score) \\
\hline \multirow[t]{5}{*}{ T2D } & LT & $55.0 \pm 26.0$ & $13.0 \pm 1.2$ & $2.9 \pm 0.6$ & $126.4 \pm 14.1$ & $13.0 \pm 2.1$ \\
\hline & LV & $58.3 \pm 23.0$ & $13.3 \pm 1.8$ & $3.0 \pm 1.0$ & $128.8 \pm 14.4$ & $13.2 \pm 2.0$ \\
\hline & HRVT-RMSSD & $58.3 \pm 17.5$ & $13.3 \pm 1.1$ & $3.0 \pm 0.7$ & $128.2 \pm 8.9$ & $13.6 \pm 1.4$ \\
\hline & HRVT-SD1 & $50.0 \pm 15.0$ & $13.0 \pm 2.1$ & $2.8 \pm 0.9$ & $123.2 \pm 6.9$ & $12.9 \pm 1.8$ \\
\hline & Exhaustion & $96.7 \pm 33.6 \neq$ & $20.6 \pm 4.6 \neq$ & $6.5 \pm 2.5 \neq$ & $159.7 \pm 20.8 \neq$ & $18.4 \pm 1.6 \neq$ \\
\hline \multirow[t]{5}{*}{ ND } & LT & $85.5 \pm 33.2^{*}$ & $19.2 \pm 5.9^{*}$ & $3.6 \pm 0.6^{*}$ & $139.3 \pm 17.4$ & $14.3 \pm 1.4$ \\
\hline & LV & $91.5 \pm 28.7^{*}$ & $20.3 \pm 5.6^{*}$ & $4.1 \pm 1.1^{*}$ & $143.1 \pm 16.2$ & $14.6 \pm 1.2$ \\
\hline & HRVT-RMSSD & $85.5 \pm 34.7^{*}$ & $19.0 \pm 5.3^{*}$ & $3.5 \pm 0.7$ & $137.7 \pm 13.1$ & $13.9 \pm 1.2$ \\
\hline & HRVT-SD1 & $82.5 \pm 34.1^{*}$ & $18.6 \pm 5.3^{*}$ & $3.2 \pm 0.7$ & $131.2 \pm 13.8$ & $13.7 \pm 1.2$ \\
\hline & Exhaustion & $135.0 \pm 45.3 \neq$ & $29.4 \pm 6.8 \neq$ & $7,7 \pm 2.0 \neq$ & $173.6 \pm 9.3 \neq$ & $18.8 \pm 1.3 \neq$ \\
\hline
\end{tabular}

Exhaustion in T2D ( $\mathrm{n}=9)$ and ND ( $\mathrm{n}=10)$.

T2D = individuals with type 2 diabetes; ND = individuals without type- 2 diabetes; ${ }^{*} p<0.05$ in relation to corresponding results for T2D; $\neq p<0.05$ in relation to the thresholds (LT, TV, HRVT RMSSD and HRVT-SD1). No differences were observed within groups for the methods to identify anaerobic threshold intensities. 
Table 3 Relationship among intensities (W) corresponding to the studied thresholds for T2D $(n=9)$ and ND $(n=10)$

\begin{tabular}{ccccc}
\hline & & LT (W) & VT (W) & HRVT-RMSSD (W) \\
\hline T2D & VT (W) & $0.83^{*}$ & - & - \\
& HRVT-RMSSD(W) & $0.85^{*}$ & $0.83^{*}$ & - \\
& HRVT-SD1 (W) & $0.87^{*}$ & $0.76^{*}$ & $0.68^{*}$ \\
& & & & - \\
ND & VT (W) & $0.95^{*}$ & - & - \\
& HRVT-RMSSD (W) & $0.94^{*}$ & $0.91^{*}$ & $0.98^{*}$ \\
& HRVT-SD1 (W) & $0.96^{*}$ & $0.93^{*}$ & \\
\hline
\end{tabular}

T2D = Type 2 diabetes mellitus individuals; ND = non diabetics individuals; $\mathrm{LT}=$ Lactate threshold; $\mathrm{VT}=$ ventilatory threshold; HRVT-RMSSD = heart rate variability threshold for RMSSD; HRVT-SD1 = heart rate variability threshold for SD1. *significant correlation $\mathrm{p}<0.01$.

activity and thus to an increased probability for the occurrence of cardiovascular events T2D individuals. Therefore, the identification of the HRVT intensity may be a safe and useful procedure for exercise evaluation and prescription.

Another benefit of HRVT identification is the avoidance of elevated financial costs usually associated with invasive methods. Exercise tests involving blood collection and biochemical measures, and/or the use of expensive apparatus for expired gases analysis, as well as trained professionals dealing with such protocols are expensive and thus of difficult access to a major part of the population.

It has been suggested that vagal withdraw progressively occurs during IT, and is almost completely inhibited at intensities around 50-60\% $\mathrm{VO}_{2 \max }[16,29]$. For the T2D participants of the present investigation, the vagal withdrawal, as observed by the RMSSD and SD1 stabilization, occurred at intensities corresponding to $64.8 \%$ and $66.6 \%$ of $\mathrm{VO}_{2 \text { peak }}$, respectively. Previous studies with T2D also verified similar results regarding LT occurring at intensities around $66 \% \mathrm{VO}_{2 \text { peak }}[4,34,35]$ what, in turn, may be of practical application.
The fact that participants of the present study had their HRVT being reached at 64.2 to $66.6 \% \mathrm{VO}_{2 \text { peak }}$ may be at least partially explained by their low physical fitness $\left(\mathrm{VO}_{2 \text { peak }}\right.$ of $20.6 \pm 4.3 \mathrm{~mL} \cdot \mathrm{kg}^{-1} \cdot \mathrm{min}^{-1}$ for T2D and $29.4 \pm 6.8 \mathrm{~mL} \cdot \mathrm{kg}^{-1} \cdot \mathrm{min}^{-1}$ for ND). This finding was also observed in a previous study comparing sedentary T2D individuals to physically active T2D and ND counter partners [35]. Moreira et al. also observed a trend towards lower [Lac] during the IT for T2D group, suggesting lower motor units recruitment and thus lower anaerobic glycolytic activity, lower power output, blood lactate and $\mathrm{VO}_{2}$ at the exhaustion moment as compared to ND, similar to what happened in present study [34].

The RPE may also be an interesting noninvasive tool for exercise evaluation and prescription for both T2D and ND. The RPE integrates cardiovascular, respiratory, neuromuscular and metabolic inputs as a result of increasing exercise intensity [36]. Some studies have demonstrated that during incremental exercise test, RPE scores around 12-13, as measured through the 15-point Borg scale, is related to attainment of the AT $[2,9]$. It was observed that RPE scores corresponding to AT in present study were around $12.9 \pm 1.8$ to $13.6 \pm 1.4$ for T2D, and $13.7 \pm 1.2$ to $14.6 \pm 1.2$ for ND (Table 2). The use of RPE for controlling exercise intensities may be an useful tool to ensure exercise prescription for T2D, once the RPE of 12-14 may help to delimitate the transition of moderate exercise to exercise intensities which eliciting blood glucose to increase $[2,8,37,38]$.

One of the limitations of present study was that the maximal lactate steady state (MLSS) intensity was not determined for comparison to the studied protocols. The MLSS determination is considered the gold standard method among those of exercise evaluation through blood lactate response to exercise. Denadai et al. [39] and Van Schuylenbergh et al. [40] have shown this parameter to be highly correlated and not different to the LT and VT intensities. So we may suggest that

Table 4 Agreement between $\mathrm{VO}_{2}$ corresponding to LT, VT and HRVT-RMSSD and HRVT-SD1 for type 2 diabetes mellitus individuals $(n=9)$ and non diabetes individuals $(n=10)$

\begin{tabular}{ccccc}
\hline Groups & Reference methods & Testing methods & Mean of differences & Limits of Agreement \\
\hline T2D & LT & HRVT-RMSSD & 0.3 & \pm 2.0 \\
& LT & HRVT-SD1 & 0.1 & \pm 4.6 \\
VT & HRVT-RMSSD & 0.1 & \pm 4.1 \\
VT & HRVT-SD1 & 0.5 & \pm 4.9 \\
& & & -0.3 & \pm 4.2 \\
ND & LT & HRVT-RMSSD & 0.3 & \pm 2.9 \\
& LT & HRVT-SD1 & 1.3 & \pm 5.9 \\
VT & HRVT-RMSSD & 0.9 & \pm 6.2 \\
\hline
\end{tabular}

T2D = Type 2 diabetes individuals; ND = non diabetes individuals; LT = lactate threshold; VT = ventilatory threshold; HRVT-RMSSD = Heart rate variability threshold for RMSSD; HRVT-SD1 = Heart rate variability threshold for SD1. 


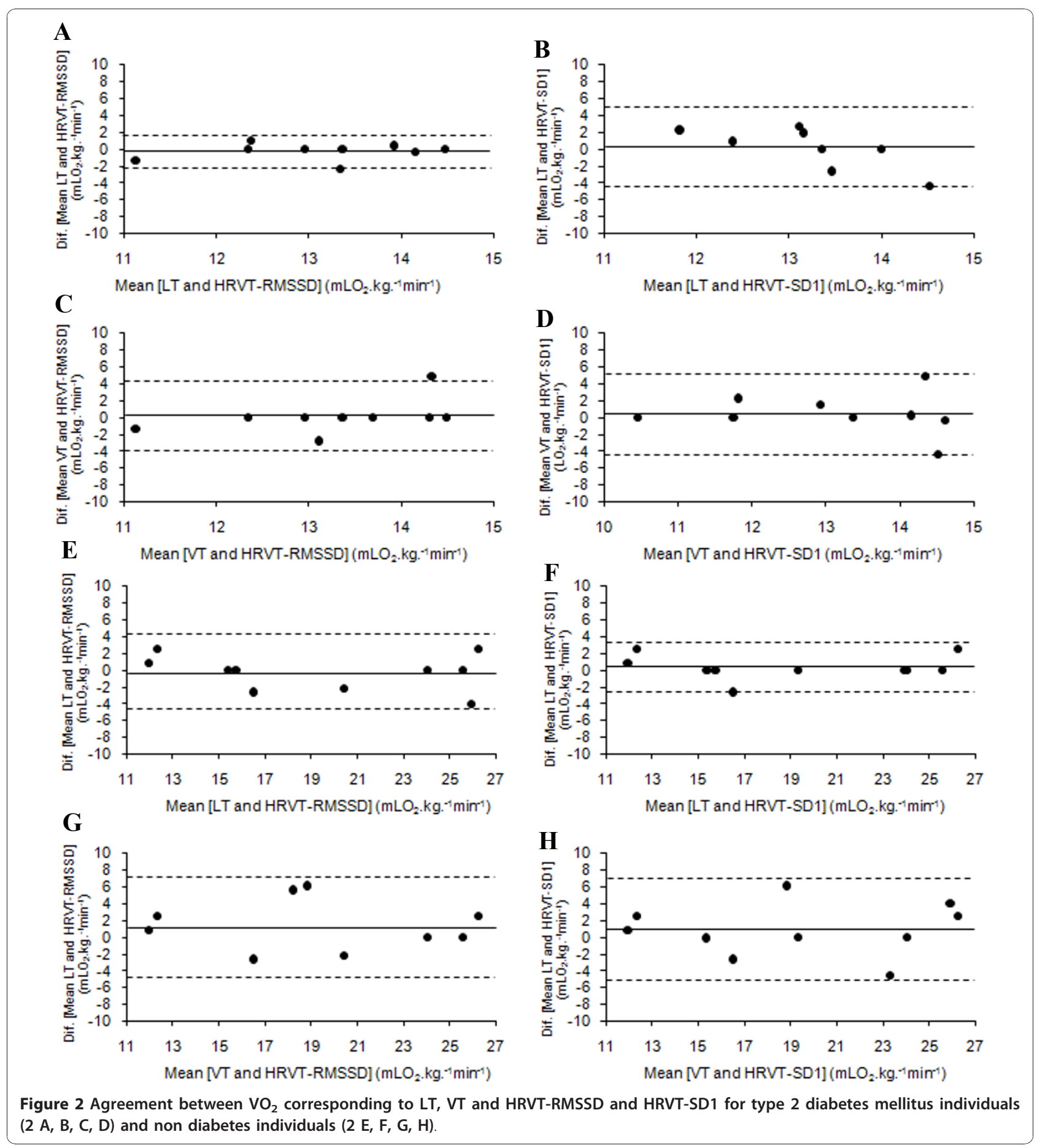

the methods adopted on present study (LT and VT determinations), which did not differ from HRVT, would also represent the MLSS intensity.

Several investigations have shown a relationship between the exercise intensity at which the vagal withdrawn is observed with those corresponding to VT $[15,41]$ and LT $[10,26]$. In the present study the HRVT, as identified through the quantitative analyses of the Poincare plots (SD1), occurred at exercise intensities not different to the LT and VT. On the other hand, in spite of non-detectable statistical differences, the exercise intensities associated to the occurrence of the HRVT-SD1 trend to be slightly lower than LT and VT for both T2D and ND, but without statistical difference $(p>0.05)$. Similarly to our findings, 
Shibata et al. [42] observed that HR corresponding to the HRVT was lower than VT, and the authors suggested that vagal withdrawal would precede the VT occurrence during IT. It is expected that mechanisms responsible for homeostasis during exercise may be related to the occurrence of both VT and LT, and is also dependent to the sympathetic/parasympathetic balance. Thus, it is reasonable that the HRVT occurs at exercise intensities closely related to LT and VT intensities. Thus, once the HRVT identified by the RMSSD seemed to better predicts the LT and VT as evidenced by the Bland and Altman analysis, we may suggest that RMSSD may be a more accurate variable and thus should be preferred in relation to SD1.

In conclusion it was possible to identify the HRVT from autonomic indices (RMSSD and SD1) for both T2D and ND, with no differences in relation to LT and VT. Furthermore, high correlations and good agreement between the examined methods were observed, suggesting the validity of HRVT even for T2D. Additional studies are necessary to investigate the reproducibility and sensitivity of AT as identified by HRV measures to various interventions, including physical training.

\section{Acknowledgements}

Capes/PROCAD (process n0216054), CNPq, Micromed and Salvapé.

\begin{abstract}
Author details
${ }^{1}$ Graduate program in Physical Education of the Catholic University of Brasilia, Águas Claras, Taguatinga-DF, 72022-900, Brazil. ²Physical Education Faculty of the North University of Parana, Paris avenue, 675, Jardim Piza Londrina - Paraná, 86041-120, Brazil. ${ }^{3}$ Physical Education Faculty of the Federal Institute of Roraima, Capitão Júlio Bezerra avenue, 1392, Aparecida, Boa Vista - Roraíma, 69303-340, Brazil. ${ }^{\circ}$ Departament of Physiology and Biophysics - Federal University of Minas Gerais, Antônio Carlos avenue, 6627, Pampulha, Belo Horizonte - Minas Gerais, 31270-901, Brazil. ${ }^{5}$ Physical Education Faculty of the Federal University of Vale do São Francisco, José de Sá Maniçoba avenue, Center, Petrolina - Pernambuco, 56304-205, Brazil. ${ }^{6}$ Graduate program in Physical Education of the State University of Londrina, Celso Garcia Cid highway, 380 kilometer, Londrina - Paraná, 86051-980, Brazil.
\end{abstract}

\section{Authors' contributions}

MMS, CSGC, PKM and HGS participated in the design of the study. MMS, PKM, PR, DFM and CE performed the data collection. MMS, LFSC, FYN performed the statistical analysis. MMS, DFM, SRM and HGS wrote the manuscript. All authors read and approved the final manuscript.

\section{Competing interests}

The authors declare that they have no competing interests.

Received: 2 June 2010 Accepted: 12 January 2011

Published: 12 January 2011

\section{References}

1. Svedahl K, Maclntosh B: Anaerobic threshold: The concept and methods of measurement. Can J Appl Physiol 2003, 28:299-323.

2. Simões H, Campbell C, Kushnick M, Nakamura A, Katsanos C, Baldissera V, Moffatt R: Blood glucose threshold and the metabolic responses to incremental exercise tests with and without prior lactic acidosis induction. Eur J Appl Physiol 2003, 89:603-611.

3. Belli T, Ackermann M, Ribeiro L, Langeani R, Galdino da Silva R, Baldissera V: Lactate and ventilatory thresholds in type 2 diabetic women. Diabetes Res Clin Pract 2007, 76:18-23.
4. Motta D, Lima L, Arsa G, Russo P, Sales M, Moreira S, Morais P, Almeida W, Araujo R, Moraes M, Pesquero J, Simões $\mathrm{H}$, Campbell C: Effect of type 2 diabetes on plasma kallikrein activity after physical exercise and its relationship to post-exercise hypotension. Diabetes Metab 2010, 36:363-368.

5. Zanuso S, Jimenez A, Pugliese G, Corigliano G, Balducci S: Exercise for the management of type 2 diabetes: A review of the evidence. Acta Diabetol 2010, 47:15-22.

6. Farsidfar F, Kasikcioglu E, Oflaz H, Kasikcioglu D, Meric M, Umman S: Effects of different intensities of acute exercise on flow-mediated dilatation in patients with coronary heart disease. Int J Cardiol 2008, 124:372-374.

7. Moreira S, Arsa G, Oliveira H, Lima L, Campbell C, Simões H: Methods to identify the lactate and glucose thresholds during resistance exercise for individuals with type 2 diabetes. J Strength Cond Res 2008, 22:1108-1115.

8. Simões H, Grubert Campbell C, Kokubun E, Denadai B, Baldissera V: Blood glucose responses in humans mirror lactate responses for individual anaerobic threshold and for lactate minimum in track tests. Eur J Appl Physiol Occup Physiol 1999, 80:34-40.

9. Kunitomi M, Takahashi K, Wada J, Suzuki H, Miyatake N, Ogawa S, Ohta S, Sugimoto H, Shikata K, Makino H: Re-evaluation of exercise prescription for japanese type 2 diabetic patients by ventilatory threshold. Diabetes Res Clin Pract 2000, 50:109-115.

10. Karapetian $\mathrm{G}$, Engels $H$, Gretebeck $R$ : Use of heart rate variability to estimate LT and VT. Int J Sports Med 2008, 29:652-657.

11. Malik MBJ, Camm AJ, Kleiger RE, Malliani A, Moss AJ, Schwartz PJ: Heart rate variability. Standarts of measurement, physiological interpretation. And clinical use. Eur Heart J 1996, 17:354-381.

12. Karemaker J, Lie K: Heart rate variability: A telltale of health or disease. Eur Heart I 2000, 21:435-437.

13. Chiou C, Zipes D: Selective vagal denervation of the atria eliminates heart rate variability and baroreflex sensitivity while preserving ventricular innervation. Circulation 1998, 98:360-368.

14. Warren J, Jaffe R, Wraa C, Stebbins C: Effect of autonomic blockade on power spectrum of heart rate variability during exercise. Am J Physiol 1997, 273:R495-502.

15. Tulppo M, Mäkikallio T, Takala T, Seppänen T, Huikuri H: Quantitative beatto-beat analysis of heart rate dynamics during exercise. Am J Physiol 1996, 271:H244-252.

16. Jermendy G: Clinical consequences of cardiovascular autonomic neuropathy in diabetic patients. Acta Diabetol 2003, 40(2):S370-374.

17. Tentolouris N, Argyrakopoulou G, Katsilambros N: Perturbed autonomic nervous system function in metabolic syndrome. Neuromolecular Med 2008.

18. Carnethon M, Jacobs DJ, Sidney S, Liu K: Influence of autonomic nervous system dysfunction on the development of type 2 diabetes: The cardia study. Diabetes Care 2003, 26:3035-3041.

19. Boulton A, Vinik A, Arezzo J, Bril V, Feldman E, Freeman R, Malik R, Maser R, Sosenko J, Ziegler D: Diabetic neuropathies: A statement by the american diabetes association. Diabetes Care 2005, 28:956-962.

20. Frontoni S, Bracaglia D, Gigli F: Relationship between autonomic dysfunction, insulin resistance and hypertension, in diabetes. Nutr Metab Cardiovasc Dis 2005, 15:441-449.

21. Rohlfing C, Wiedmeyer H, Little R, England J, Tennill A, Goldstein D: Defining the relationship between plasma glucose and $\mathrm{hba}(1 \mathrm{c})$ : Analysis of glucose profiles and hba(1c) in the diabetes control and complications trial. Diabetes Care 2002, 25:275-278.

22. Gamelin F, Berthoin $\mathrm{S}$, Bosquet L: Validity of the polar $s 810$ heart rate monitor to measure r-r intervals at rest. Med Sci Sports Exerc 2006, 38:887-893.

23. Wasserman K, Mcilroy M: Detecting the threshold of anaerobic metabolism in cardiac patients during exercise. Am J Cardiol 1964, 14:844-852.

24. Howley E, Bassett DJ, Welch H: Criteria for maximal oxygen uptake: Review and commentary. Med Sci Sports Exerc 1995, 27:1292-1301.

25. Brunetto AF, Hirai DM, Ronque EV, Guedes DP: Heart rate variability threshold in obese and non-obese adolescents. Rev Bras Med Esporte 2008, 4:145-149.

26. Lima JRP, Kim M: Heart rate variability threshold. Rev Bras Ativ Fís Saúde 1999, 4:29-38.

27. Bland J, Altman D: Statistical methods for assessing agreement between two methods of clinical measurement. Lancet 1986, 1:307-310. 
28. Bhagyalakshmi S, Nagaraja H, Anupama B, Ramesh B, Prabha A, Niranjan M, Shreedhara A: Effect of supervised integrated exercise on heart rate variability in type 2 diabetes mellitus. Kardiol Pol 2007, 65:363-368.

29. Sztajzel J: Heart rate variability: A noninvasive electrocardiographic method to measure the autonomic nervous system. Swiss Med Wkly 2004, 134:514-522.

30. Yeckel C, Gulanski B, Zgorski M, Dziura J, Parish R, Sherwin R: Simple exercise recovery index for sympathetic overactivity is linked to insulin resistance. Med Sci Sports Exerc 2009, 41:505-515.

31. Caballero A: Endothelial dysfunction in obesity and insulin resistance: A road to diabetes and heart disease. Obes Res 2003, 11:1278-1289.

32. McGirt M, Woodworth G, Brooke B, Coon A, Jain S, Buck D, Huang J, Clatterbuck R, Tamargo R, Perler B: Hyperglycemia independently increases the risk of perioperative stroke, myocardial infarction, and death after carotid endarterectomy. Neurosurgery 2006, 58:1066-1073.

33. Tsuji H, Larson M, Venditti FJ, Manders E, Evans J, Feldman C, Levy D: Impact of reduced heart rate variability on risk for cardiac events. The framingham heart study. Circulation 1996, 94:2850-2855.

34. Moreira SR, Simões GC, Hiyane WC, Campbell CSG, Simões HG: Identification of the anaerobic threshold in sedentary and physically active individuals with type 2 diabetes. Rev Bras Fisioter 2007, 7:289-296.

35. Lima L, Assis G, Hiyane W, Almeida W, Arsa G, Baldissera V, Campbell C, Simões $\mathrm{H}$ : Hypotensive effects of exercise performed around anaerobic threshold in type 2 diabetic patients. Diabetes Res Clin Pract 2008, 81:216-222.

36. Borg G: Psychophysical bases of perceived exertion. Med Sci Sports Exerc 1982, 14:377-381.

37. Simões HG, Moreira SR, Moffatt RJ, Campbell CSG: Métodos para identificar o limiar anaeróbio em indivíduos com diabete tipo 2 e em indivíduos não-diabéticos. Arq Bras Cardiol 2010, 94:71-78.

38. Simões $H G$, Moreira SR, Hiyane WC, Benford RE, Madrid B, Prada FA, Oliveria RJ, Nakamura FY, Campbell CSG: Lactate Threshold prediction by blood glucose and rate perceived exertion in people with type 2 diabetes. Percept Mot Skills 2010, 111:1-114.

39. Denadai B, Figueira T, Figuera T, Favaro O, Gonçalves M: Effect of the aerobic capacity on the validity of the anaerobic threshold for determination of the maximal lactate steady state in cycling. Braz J Med Biol Res 2004, 37:1551-1556.

40. Van Schuylenbergh R, Vanden Eynde B, Hespel P: Correlations between lactate and ventilatory thresholds and the maximal lactate steady state in elite cyclists. Int I Sports Med 2004, 25:403-408.

41. Yamamoto $Y$, Hughson R, Peterson J: Autonomic control of heart rate during exercise studied by heart rate variability spectral analysis. J Appl Physiol 1991, 71:1136-1142.

42. Shibata M, Moritani T, Miyawaki T, Hayashi T, Nakao K: Exercise prescription based upon cardiac vagal activity for middle-aged obese women. Int $J$ Obes Relat Metab Disord 2002, 26:1356-1362.

doi:10.1186/1758-5996-3-1

Cite this article as: Sales et al:: Noninvasive method to estimate anaerobic threshold in individuals with type 2 diabetes. Diabetology \& Metabolic Syndrome 2011 3:1.

\section{Submit your next manuscript to BioMed Central and take full advantage of:}

- Convenient online submission

- Thorough peer review

- No space constraints or color figure charges

- Immediate publication on acceptance

- Inclusion in PubMed, CAS, Scopus and Google Scholar

- Research which is freely available for redistribution

Submit your manuscript at www.biomedcentral.com/submit 